\title{
Washing with hope: evidence of improved handwashing among children in South Africa from a pilot study of a novel soap technology
}

\author{
Justine Burns ${ }^{*}$, Brendan Maughan-Brown ${ }^{2}$ and Âurea Mouzinho ${ }^{3}$
}

\begin{abstract}
Background: While regular handwashing effectively reduces communicable disease incidence and related child mortality, instilling a habit of regular handwashing in young children continues to be a challenging task, especially in developing country contexts. This randomised controlled pilot study assessed the effect of a novel handwashing intervention - a bi-monthly delivery of a colourful, translucent bar of soap with a toy embedded in its centre (HOPE SOAP() - on children's handwashing behaviour and health outcomes.

Methods: Between September and December 2014, 203 households in an impoverished community in Cape Town, South Africa, were randomised (1:1) to the control group or to receive HOPE SOAPO. Of all children $(N=287)$ aged 3-9 years and not enrolled in early childhood development programmes, 153 residing in intervention households received a bar of HOPE SOAP@ every two weeks (total of 4 bars). Children in control households received a colourful, translucent bar of soap of equal size to HOPE SOAP@, with a toy alongside it. Two 'snack tests' (children were offered crackers and jam) were used to provide objective observational measures of handwashing. Through baseline and endline surveys, data were collected from caregivers on the frequency (scale of 1-10) of handwashing by children after using the toilet and before meals, and on soap-use during handwashing. Data on 14 illnesses/ symptoms of illness experienced by children in the two weeks preceding the surveys were collected. Multivariable Ordinary Least Squares regression analyses were used to assess the intervention effect on handwashing behaviours and health outcomes.
\end{abstract}

Results: At endline, HOPE SOAPO children were directly observed as being more likely to wash their hands unprompted at both snack tests ( $49 \%$ vs $39 \%, \beta: 0.10, p=0.27$ ). They were more likely to score $\geq 8 / 10$ for using soap when washing their hands $(\beta: 0.14, p=0.011)$. HOPE SOAP@ children, in general, had better health outcomes, and those who used the soap as intended, and did not cheat to remove the toy from the soap, were less likely to have been ill $(\beta:-0.15, p=0.049)$.

Conclusions: Results point towards HOPE SOAP@ being an effective intervention to improve handwashing among children. Further research on this novel handwashing intervention is warranted.

Trial registration: NCT03280771 (www.clinicaltrials.gov) retrospectively registered on 8 September 2017.

Keywords: Handwashing intervention, Childhood health, Pilot randomised controlled trial, Behavioural economics, Development economics, Habit formation

\footnotetext{
* Correspondence: justine.burns@uct.ac.za

${ }^{1}$ School of Economics, University of Cape Town, Private Bag, Rondebosch

7701, South Africa

Full list of author information is available at the end of the article
}

(c) The Author(s). 2018 Open Access This article is distributed under the terms of the Creative Commons Attribution 4.0 International License (http://creativecommons.org/licenses/by/4.0/), which permits unrestricted use, distribution, and reproduction in any medium, provided you give appropriate credit to the original author(s) and the source, provide a link to the Creative Commons license, and indicate if changes were made. The Creative Commons Public Domain Dedication waiver (http://creativecommons.org/publicdomain/zero/1.0/) applies to the data made available in this article, unless otherwise stated. 


\section{Background}

Preventable disease continues to be a leading cause of child deaths around the world. Diarrhoea and acute respiratory infections are responsible for 35 and $32 \%$ of child deaths respectively [1], whilst communicable diseases have been estimated to be responsible for $73 \%$ of deaths of children under the age of five years [2]. Furthermore, early childhood disease has been shown to have potential long-term human and economic costs by impacting future school readiness and achievement, outcomes in early adulthood, and performance on cognitive tests in old age [3-7].

Regular handwashing holds promise as a cheap and effective way to reduce communicable disease incidence and related child mortality in developing countries [8]. However, instilling a habit of regular handwashing in young children continues to be a challenging task, especially in developing country contexts, where it has been estimated in various studies that only $3-35 \%$ of individuals wash their hands at critical times [9]. The available literature suggests a number of key insights that are important in this regard. The first is that, on its own, the provision of information about the importance of handwashing may be necessary but not sufficient to lead to improved health outcomes. For example, mass media or information campaigns to promote handwashing appear to be largely ineffective $[8,10]$. Recent work in behavioural science suggests that the failure of these interventions may stem from too great a reliance on conscious, deliberate thought and assimilation of knowledge to lead to behaviour change, when, in fact, many of these desired behaviours are automatic, largely unreflective and prompted by contextual cues [11-13]. Thus, if the goal is to induce habit formation, greater attention must be paid to System I thinking, which is far more automatic, unconscious and cue-driven [12]. For example, when soap and water are readily available, thereby providing a critical behavioural cue $[12,14]$, handwashing behaviour and health outcomes tend to improve on average [15, 16]. Inducing desired behaviour among children may further require leveraging context to produce a teachable moment [8], such as teaching proper handwashing technique and promoting the importance of handwashing at key times, namely prior to food preparation and after toilet use $[12,17]$.

The difficulty in translating interventions into behavioural change among children, and ultimately improved health outcomes among children, stems from the multiple factors that need to be aligned for success. For example, caregivers may fail to effectively transfer information from education campaigns to children. These difficulties in handwashing campaigns raise the possibility that targeting children directly may be more effective to achieve behavioural change. In addition, many handwashing studies rely on self-reported measures of handwashing behaviour which may be subject to bias. Obtaining objectively verified observational measures of handwashing is a challenge for any study of handwashing behaviour, with proposed solutions ranging from the use of costly acceleration sensors to direct observation. However, typical methods employed to measure handwashing via direct observation may lead to an overestimate of handwashing by as much as $20 \%$ [18].

In this study we assessed the effect on handwashing and health outcomes of a novel glycerine bar of soap, HOPE SOAP $\odot$, that included a child-friendly toy at the centre which could be accessed through regular handwashing. We tested a novel data collection technique designed to minimize bias in typical handwashing measures by adding a 'snack test' to a pre-existing programme, and using the programme implementers already familiar to children to collect a directly observable measure of handwashing. Thus, by relying on a randomised controlled trial in conjunction with a minimally-intrusive, directly observable measure of handwashing behaviour, this study hopes to overcome some of the difficulties that have plagued previous studies. In addition, this study adds to the limited experimental evidence in an African context on the efficacy of a handwashing intervention targeting children directly.

\section{Methods}

Our study was conducted between September and December of 2014 in the impoverished community of Delft in the Western Cape, South Africa. Delft is a township on the outskirts of Cape Town (approximately $34 \mathrm{~km}$ from the centre of the city) consisting largely of government housing projects within an area of approximately $11 \mathrm{~km}^{2}$. The study was implemented in partnership with the Foundation for Community Work (FCW), an early childhood development and resource organisation. FCW runs an in-home education programme called Family-in-Focus, which involves fortnightly home-visits conducted by trained community workers, during which they engage with caregivers and their children, sharing knowledge on child development and facilitating activities to promote caregiver-child interaction. The community of Delft was selected as the pilot site because it has been identified by the provincial Department of Health with a high burden of diarrhoea [19], and due to the large number of households and children in the area enrolled in the Family-in-Focus programme. At the start of the implementation period, the study site was served by 13 community workers.

Eligibility for inclusion in the pilot was based on the following criteria: (1) the caregiver was participating in the FCW Family-in-Focus programme; (2) the caregiver had at least one child between the ages of three and nine years old in the programme; (3) the age-eligible children 
were not involved in any other sort of early childhood development programme (eg, crèche or other day-care). Eligibility was based on caregivers and not households, since a single household could contain more than one caregiver. The child age-bracket was based on the fact that FCW do not work with children older than nine, and that they only start targeting children with hygiene and handwashing messages once they turn three.

\section{The intervention: HOPE SOAP $\odot$}

HOPE SOAP( ${ }^{1}$ is a colourful, translucent bar of soap with a toy embedded in its centre. The aim of this innovative yet simple soap technology is to encourage handwashing practice among children by making it fun and goal-oriented. HOPE SOAP $\odot$ is smaller than typical bars of soap used by households in the study area, with dimensions of 50 millimetres $(\mathrm{mm})$ by $44 \mathrm{~mm}$ by $24 \mathrm{~mm}$. A range of toys, such as a bouncing ball and a plastic fish, were used.

\section{The control group soap}

Children in the control group received soap with the same specifications as HOPE SOAP $\odot$ (a colourful, translucent bar of the same size), but there was no toy embedded in the centre of the control group soap. Since households assigned to treatment and control arms of the study could live close to one another, this raised the possibility that children in control households would learn about HOPE SOAP $\odot$ and possibly become disgruntled by not receiving a toy and thus be less inclined to use their soap, or conversely, might try to assist children in treatment households in getting the toy out of the soap by also using it. To minimise these behaviours, and associated potential confounds on our treatment effect, children in control households received the control group soap together with a toy alongside the soap. These toys were the same as those placed inside HOPE SOAP@. Thus, the control group soap was also smaller than typical soap used in the area, and came in a greater variety of colours. We refer to this soap as 'control' soap.

\section{Randomisation}

Using a randomised trial, our pilot study was designed to test whether HOPE SOAP $\odot$, in comparison to 'control' soap, increases handwashing among young children, both in the short-term and in the long-term (ie, habit formation), and results in better health outcomes. Because assignment to treatment was random, receipt of the intervention was exogenous, and therefore unrelated to any other observable and unobservable factors [20]. This solves problems of selection bias and unobserved heterogeneity. The sample frame for this study consisted of all residential addresses in Delft $(N=203)$ provided by FCW at which a child (3-9 years old) was enrolled in their Family-in-Focus programme. All caregivers enrolled in the Family-in-Focus programme at these residences participated in our study. Since intra-household spillovers in soap usage would be difficult to prevent and measure, we randomised (1:1) to either HOPE SOAP $\odot$ or the control soap at the household level $(n=$ 203) using the statistical software package Stata 14 (Stata Corporation LP, College Station, TX). All study eligible children residing in each household were assigned to the same study group. We stratified the randomisation by community worker, household size, the gender and age ratio among eligible children, and the number of caregivers in the household. Although a third group of comparison households in which eligible children received nothing would have been ideal, binding budget constraints for the pilot made this impossible.

\section{Intervention delivery}

The Family-in-Focus programme formally addresses issues of child health and handwashing in its content, providing an ideal platform to roll out the HOPE SOAPC pilot intervention. Figure 1 outlines the schedule of soap deliveries. The first delivery of soap into households was made by community workers, one week after the baseline survey, to the families assigned to them in the Family-in-Focus programme. Before giving the first bar of soap to children, the community workers provided the single standard lesson on health and hygiene that was designed for the Family-in-Focus programme (see Additional file 1 for details on the content of the lesson). The single health and hygiene lesson was provided to all caregivers and children (ie, in both the treatment and control households) to ensure equal exposure to this information at the start of the intervention. The soap was packaged in brown paper parcels by the research team and labelled with the child's name to ensure (1) that a sense of ownership was created for children, and (2) that community workers were blinded to group assignment while providing the education lesson.

Subsequent to the first delivery of soap, the intervention consisted of fortnightly provision of HOPE SOAPC bars to children in treatment households and control soap with a toy alongside to children in control households over a 6-week period. All children in the study received four bars of soap. All soap was labelled with the child's name and packaged in brown paper parcels by the research team. These soap deliveries were conducted by an independent team (ie, not the community workers) so as to ensure that study group assignment remained fixed throughout the study. Deliveries were typically made at a time when community workers were not visiting families. Soap was delivered to children's caregivers and no additional health education was provided. 


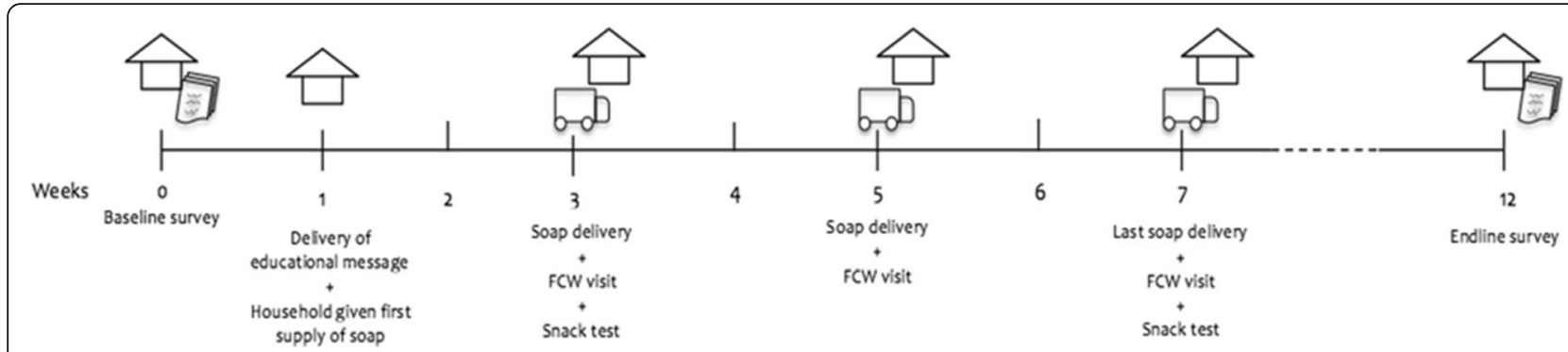

Fig. 1 Timeline of intervention and data collection for the HOPE SOAP@ pilot study

\section{Data and measures}

Figure 1 provides the timeline for data collection. A baseline survey was conducted in September 2014 to collect household characteristics (ie, composition, infrastructures, assets, health), knowledge about health and hygiene practices, as well as attitudes and behaviour towards handwashing. Additional observational data on soap availability and household cleanliness were also collected. An endline survey was conducted shortly after the intervention period ended in December 2014. The baseline survey was repeated with additional data being collected on usage of and attitude towards HOPE SOAPC. The baseline and endline surveys were administered by an independent research team (ie, not by community workers).

The baseline and endline surveys collected self-reported data from caregivers on the frequency of soap use and handwashing by children at two critical times, namely, after the toilet and before meals. Specifically, caregivers were asked 'On a scale of 1 to 10 , where 1 means never and 10 means always, how regularly does [...] wash his or her hands without being prompted after using the toilet?' and 'On a scale of 1 to 10 , where 1 means never and 10 means always, how regularly does [...] wash his or her hands without being prompted before a main meal?' Caregivers used the same scale to report how often the child used soap when he or she washes his or her hands. Data on child health outcomes in the two weeks preceding the survey were also collected by asking caregivers whether each child had experienced any of the following in the two weeks prior to each survey: blocked nose, runny nose, persistent sneezing, sore or scratchy throat, painful swallowing, cough, fever, headache, shortness of breath, itchy and watery eyes, nausea, vomiting, rash, diarrhoea. An illness score (0-14) was created as the sum of the number of symptoms experienced.

Between the baseline and endline surveys the community workers conducted a 'snack test' during two of the four scheduled home-visits. Here, the community worker offered a snack of crackers and jam to the children at the end of the home-visit and observed whether or not the children washed their hands unprompted before eating the snack. We use this data as our objective observational measure of handwashing to complement the caregiver-reported measures of handwashing collected during the surveys. As it was impossible to completely blind community workers to the study group assignment - community workers would return to households as part of the regular Family-in-Focus programme and could observe which soap was in a household - we attempted to minimise potential treatment effect bias associated with the non-blinded study in three ways. First, we stratified our randomisation by community workers to ensure that community workers had children in both treatment and control households. Measurement bias resulting from community workers recording a more positive outcome in order to show that her households were doing well would therefore apply for both treatment and control households, and not influence findings on the treatment effect. Second, community workers were under the impression that the study aimed to assess the impact of soap provision to households, rather than the impact of HOPE SOAP@ relative to normal soap specifically. Third, all deliveries of soap were made in brown parcels, and deliveries of soap subsequent to the first delivery were made by an independent research team at a time when the community worker was not with households. This step aimed to keep group assignment as obscure as possible to the community workers, and minimise the salience of the study in their minds.

\section{Analysis}

We first present baseline sample characteristics by assignment to study group to assess whether there were any differences in key characteristics following randomisation. Ordinary least squares regression models were used to estimate the effect of assignment to HOPE SOAP( $\odot$ on observed handwashing during the snack tests, as well as endline measures of 1) frequency of handwashing after the toilet and before meals; 2) 
frequency of soap usage when washing hands; 3) and number of symptoms of illness experienced. All standard errors were clustered by FCW community worker. By accounting for clustering at this level, we control for all potential error correlation between families served by the same FCW community worker. This includes potential correlation between family units living within the same physical structure. To increase the precision of the estimates in the multivariable models, we controlled for key demographics, and factors that could influence handwashing that had a relatively large difference $(p<0.2)$ across study groups at baseline.

\section{Results}

\section{Baseline characteristics}

Our baseline sample was recruited from 203 houses (ie, physical structures). In 22 cases, multiple caregivers with children enrolled in the FCW programme resided in the same house. These caregivers defined their family unit as a separate household despite living in the same physical structure. Accordingly, for our analysis, we defined households as separate family units rather than physical structures. Tables 1 and 2 presents baseline characteristics of the households $(N=229)$, caregivers $(N=229)$ and children $(N=288)$ in our sample.

Table 1 Baseline summary statistics: households and caregivers

\begin{tabular}{|c|c|c|c|c|c|c|c|c|c|}
\hline & \multicolumn{3}{|c|}{ Full sample } & \multicolumn{2}{|c|}{ Treatment } & \multicolumn{2}{|c|}{ Control } & \multicolumn{2}{|c|}{ Treatment-Control } \\
\hline & $n$ & Mean & SD & $n$ & Mean & $n$ & Mean & Difference & $p$-value \\
\hline \multicolumn{10}{|l|}{$\underline{\text { Household Characteristics }}$} \\
\hline Number of members & 229 & 6.47 & 2.64 & 123 & 6.42 & 106 & 6.52 & -0.10 & 0.799 \\
\hline Number of children (2 to $10 \mathrm{yrs}$. old) & 229 & 2.27 & 1.22 & 123 & 2.19 & 106 & 2.36 & -0.17 & 0.324 \\
\hline Race of household head: Coloured ${ }^{a}$ & 219 & 0.82 & 0.38 & 120 & 0.83 & 99 & 0.82 & 0.01 & 0.900 \\
\hline Household head: completed grade 12 & 189 & 0.14 & 0.35 & 105 & 0.13 & 84 & 0.14 & -0.01 & 0.855 \\
\hline Any member receives a govt. grant & 229 & 0.89 & 0.31 & 123 & 0.92 & 106 & 0.86 & 0.06 & 0.151 \\
\hline Asset index (0-20) & 223 & 9.16 & 3.15 & 121 & 9.13 & 102 & 9.19 & -0.05 & 0.906 \\
\hline Monthly household income $<$ R2000 & 214 & 0.41 & 0.49 & 113 & 0.42 & 101 & 0.40 & 0.02 & 0.779 \\
\hline Piped water in house & 228 & 0.79 & 0.41 & 123 & 0.73 & 105 & 0.85 & -0.12 & 0.041 \\
\hline Toilet in house & 226 & 0.87 & 0.34 & 122 & 0.84 & 104 & 0.90 & -0.06 & 0.196 \\
\hline Household limits water use ${ }^{b}$ & 214 & 0.44 & 0.50 & 110 & 0.50 & 104 & 0.39 & 0.12 & 0.096 \\
\hline \multicolumn{10}{|l|}{ Hygiene \& health } \\
\hline Household uses bar soap & 226 & 0.93 & 0.26 & 121 & 0.93 & 105 & 0.92 & 0.00 & 0.962 \\
\hline Soap always available (self-report) & 226 & 0.72 & 0.45 & 121 & 0.73 & 105 & 0.71 & 0.02 & 0.716 \\
\hline Soap observed in house by fieldworker & 198 & 0.61 & 0.49 & 104 & 0.56 & 94 & 0.66 & -0.10 & 0.156 \\
\hline Household limits handwashing ${ }^{c}$ & 228 & 0.18 & 0.38 & 123 & 0.17 & 105 & 0.19 & -0.02 & 0.701 \\
\hline Any household member ill in past 2 weeks & 229 & 0.65 & 0.48 & 123 & 0.62 & 106 & 0.68 & -0.06 & 0.354 \\
\hline Any child ill in past 2 weeks & 229 & 0.42 & 0.49 & 123 & 0.38 & 106 & 0.46 & -0.08 & 0.248 \\
\hline \multicolumn{10}{|l|}{$\underline{\text { Caregiver characteristics }}$} \\
\hline FIF Programme participant $>3$ months $^{d}$ & 222 & 0.62 & 0.49 & 120 & 0.58 & 102 & 0.67 & -0.08 & 0.215 \\
\hline Received hygiene training in past 3 months & 220 & 0.61 & 0.49 & 119 & 0.56 & 101 & 0.65 & -0.09 & 0.183 \\
\hline Reported handwashing prevents diarrhoea ${ }^{e}$ & 229 & 0.61 & 0.49 & 123 & 0.60 & 106 & 0.61 & -0.01 & 0.862 \\
\hline Handwashing technique knowledge $(0-40)^{f}$ & 226 & 32.40 & 7.33 & 121 & 32.11 & 105 & 32.73 & -0.63 & 0.517 \\
\hline Washes hands before cooking \& eating & 229 & 0.78 & 0.42 & 123 & 0.79 & 106 & 0.76 & 0.02 & 0.659 \\
\hline Always uses soap to wash hands & 228 & 0.80 & 0.40 & 123 & 0.80 & 105 & 0.80 & 0.00 & 0.950 \\
\hline Health never affects activities & 228 & 0.57 & 0.50 & 122 & 0.53 & 106 & 0.60 & -0.07 & 0.278 \\
\hline Depressed/anxious 3+ days in past week & 229 & 0.56 & 0.50 & 123 & 0.60 & 106 & 0.51 & 0.09 & 0.155 \\
\hline
\end{tabular}

SD Standard deviation

a'Coloured' is a commonly used racial classification in South Africa, which describes an individual of mixed-race ancestry

${ }^{b}$ Caregivers were asked 'Can this household afford to use as much water as it needs every month, or do you have to limit your usage in any way?'

cCaregivers were asked whether their household limits handwashing to limit the amount of water used

${ }^{\mathrm{d}}$ This indicator represents caregivers who had been participating in the Family-in-Focus (FIF) programme for more than three months

'Caregivers were asked the open-ended question: 'How do you think diarrhoea can be prevented?'

fUsing a scale of 1 to 10 (1: not important, 10: very important) caregivers were asked the importance of four activities during handwashing: using soap, using warm water, rubbing hands together, lathering soap. The four responses were summed 
Of the 229 households/family units that were surveyed at baseline, 123 households were randomly assigned to treatment. The vast majority of household heads had not completed high school (86\%), and there was high reliance on government social welfare grants. Despite generally low monthly household income, basic hygiene-related infrastructure was good: $79 \%$ of households had piped water in the house and $87 \%$ reported a flush toilet within the dwelling. In terms of household hygiene (Table 1), almost all households were using bar soap. The provision of bar soap to households during our study would therefore not have introduced an unfamiliar soap product. Just over a quarter of households (28\%) reported not having soap always available and in more than a third (39\%) of households, the fieldworker did not observe soap for handwashing on the day of the baseline survey. Furthermore, just under a fifth of households reported that they limited handwashing activities in some way due to water scarcity. Reports of illness within the household were common with $65 \%$ of households reporting that at least one household member had diarrhoea, flu or nausea in the 2 weeks preceding the baseline survey, and $42 \%$ reporting the same for children.

The caregivers (Table 1) of the children in our sample had, on average, been involved with the FCW programme for a relatively short time with a mean of 5 months and $38 \%$ having enrolled in the three months prior to the baseline. Self-reported knowledge of how to effectively wash hands was high among caregivers, with an average score of 32 out of a maximum of 40 based on knowledge of four components of handwashing (the importance of soap, warm water, rubbing hands and lathering). However, 39\% did not mention handwashing as a means to prevent diarrhoea, over a fifth reported that they did not always wash hands before cooking and eating (22\%), and 20\% did not always use soap when washing hands.

Our sample of children (Table 2) comprised similar numbers of girls and boys, with an average age of four and a half. For approximately a third of children, being too short to reach the tap, having difficulty opening the tap and having hands too small to hold the soap were reported to affect handwashing most or all of the time. Factors relating to the water supply (temperature, cleanliness and smell) were also potential barriers to handwashing. In terms of handwashing behaviour, unprompted handwashing was relatively infrequent at baseline with an average of less than six on the handwashing scale (1-10:1 = never, 10 = always) for both scenarios of handwashing after the toilet and before meals. In cases when children did wash their hands, the average score for the regularity of soap

Table 2 Baseline summary statistics: children

\begin{tabular}{|c|c|c|c|c|c|c|c|c|c|}
\hline & \multicolumn{3}{|c|}{ Full sample } & \multicolumn{2}{|c|}{ Treatment } & \multicolumn{2}{|c|}{ Control } & \multicolumn{2}{|c|}{ Treatment-Control } \\
\hline & $n$ & Mean & SD & $n$ & Mean & $n$ & Mean & Difference & $p$-value \\
\hline Female & 287 & 0.49 & 0.50 & 153 & 0.49 & 134 & 0.49 & 0.00 & 0.970 \\
\hline Age & 287 & 4.48 & 1.36 & 153 & 4.46 & 134 & 4.51 & -0.04 & 0.798 \\
\hline \multicolumn{10}{|l|}{ Handwashing barriers $^{a}$} \\
\hline Too short to reach tap & 284 & 0.35 & 0.48 & 151 & 0.39 & 132 & 0.30 & 0.10 & 0.152 \\
\hline Can't open tap & 284 & 0.38 & 0.49 & 150 & 0.45 & 133 & 0.30 & 0.15 & 0.026 \\
\hline Hands too small for soap & 284 & 0.32 & 0.47 & 150 & 0.37 & 133 & 0.26 & 0.11 & 0.077 \\
\hline Water too hot/cold & 287 & 0.19 & 0.39 & 153 & 0.20 & 134 & 0.16 & 0.04 & 0.502 \\
\hline Dirty water & 287 & 0.18 & 0.38 & 153 & 0.18 & 134 & 0.16 & 0.02 & 0.739 \\
\hline Water smells bad & 287 & 0.16 & 0.37 & 153 & 0.16 & 134 & 0.16 & 0.00 & 0.998 \\
\hline Household water saving & 284 & 0.15 & 0.36 & 150 & 0.14 & 133 & 0.16 & -0.02 & 0.751 \\
\hline Sounds from water tap & 284 & 0.06 & 0.24 & 150 & 0.09 & 133 & 0.04 & 0.05 & 0.204 \\
\hline \multicolumn{10}{|l|}{ Handwashing } \\
\hline After toilet $(1-10)$ & 282 & 5.73 & 3.00 & 151 & 5.62 & 130 & 5.89 & -0.28 & 0.501 \\
\hline Before meals (1-10) & 283 & 5.35 & 2.95 & 150 & 5.16 & 132 & 5.60 & -0.44 & 0.299 \\
\hline Uses soap $(1-10)$ & 275 & 6.93 & 2.79 & 144 & 6.95 & 130 & 6.89 & 0.07 & 0.870 \\
\hline \multicolumn{10}{|l|}{ Health } \\
\hline Illness score (0-14) & 249 & 2.55 & 2.59 & 137 & 2.51 & 112 & 2.59 & -0.08 & 0.835 \\
\hline Any illness symptom & 249 & 0.74 & 0.44 & 137 & 0.77 & 112 & 0.71 & 0.07 & 0.270 \\
\hline $2+$ illness symptoms & 249 & 0.57 & 0.50 & 137 & 0.55 & 112 & 0.59 & -0.04 & 0.580 \\
\hline
\end{tabular}

SD Standard deviation

${ }^{a}$ Caregivers reported how often different factors affected their child's willingness to wash his or her hands. A binary variable was created for each factor with $1=$ all, most, or some of the time; and $0=$ none of time 
use during handwashing was 6.9 , with $49 \%$ of the children scoring an 8 or above.

A key feature to note in Tables 1 and 2 is that in almost all cases, sample attributes were balanced between the treatment and control group, with exceptions being that treatment households were significantly less likely to have piped water in the household, and were more likely to limit water use. In addition, children in treatment households were significantly more likely to be reported as having difficulty opening a tap, and as having hands that were too small to hold regular soap.

\section{HOPE SOAP $\odot$ children were directly observed as being more likely to wash their hands unprompted prior to eating a snack, although the differences were not statistically significant}

Figure 2 displays the proportion of children in treatment and control groups respectively who, without being prompted, washed their hands before eating at the first and second snack test. Similar proportions of children in both groups were observed to wash their hands prior to the first snack test (control: 56\%, treatment: 59\%). However, differences were evident by the second snack test. At snack test two, 59\% of children in the HOPE SOAP( group washed their hands compared to $48 \%$ in the control group $(p=0.215)$, indicating an $8 \%$ point decrease in handwashing at snack test two among children in the control group.

After controlling for demographic characteristics and factors that were unbalanced between treatment and control groups at baseline, treatment children were $6 \%$ points $(p=0.485)$ more likely to wash their hands before eating at snack test two (Table 3, Model 4). Moreover, children in the HOPE SOAP@ group were $10 \%$ points $(p=0.264)$ more likely to wash their hands before both snack tests compared to control group children (Table 3, Model 6). Sensitivity analysis using multivariable logistic regression models with the same specifications as the models presented in Table 3 found substantively similar results. The adjusted odds ratio for the treatment effect on washing hands at both snack tests (equivalent to Model 6, Table 3) was $1.53(p=0.279)$.

\section{Reported handwashing improved in both study groups} Figure 3 displays the change between baseline and endline in the average score for three different caregiver-reported handwashing measures. Overall, in both groups, substantial improvements in handwashing were found for both the frequency of handwashing at critical times and the use of soap when hands were washed. At endline, according to bivariate analyses, there were no significant differences in these measures among control and treatment children.

\section{Conditional on poor baseline handwashing behaviour, HOPE SOAP $\odot$ children were more likely to wash their hands after using the toilet}

The results for the effect of HOPE SOAP@ on handwashing after going to the toilet are presented in Table 4, Panel A. A weak positive treatment effect was found after controlling for baseline factors (Models A2 \& A3). However, Model A4 indicates that the treatment effect varied according to baseline handwashing score with a larger effect among children who were initially relatively poorer handwashers (treatment coefficient: 1.29, $p=0.117$ ), and a

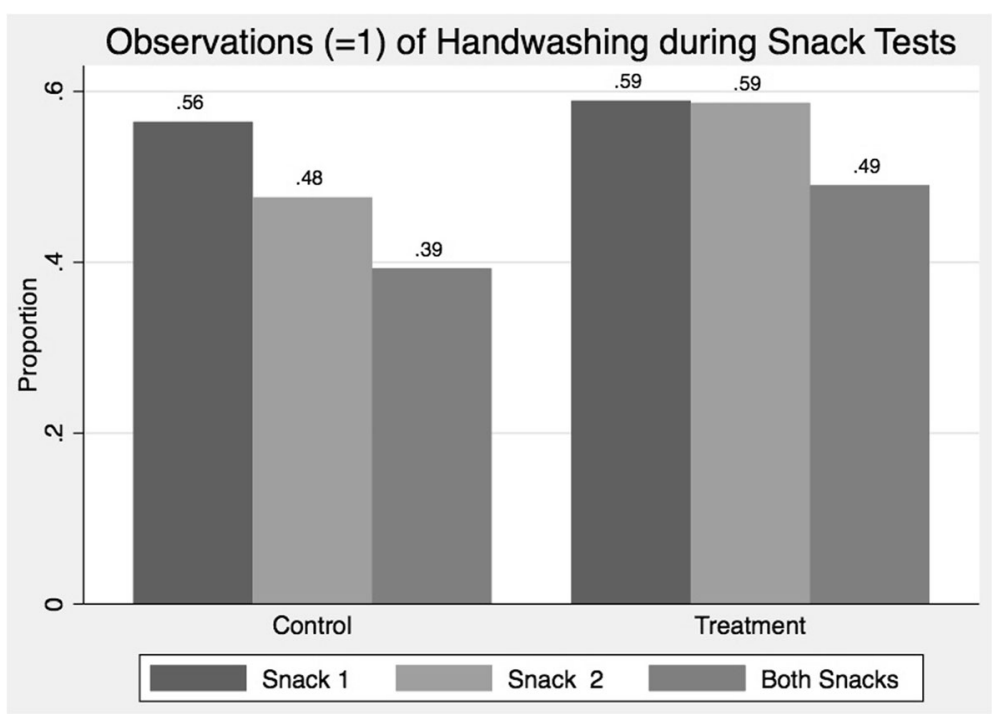

Fig. 2 Observations of handwashing among children during the snack tests 
Table 3 Ordinary least squares regression models of treatment effects on observed handwashing (yes $=1$, no $=0$ ) among children during the snack tests

\begin{tabular}{|c|c|c|c|c|c|c|}
\hline & 1 & 2 & 3 & 4 & 5 & 6 \\
\hline & $\begin{array}{l}\text { Washed at Snack } \\
1\end{array}$ & $\begin{array}{l}\text { Washed at Snack } \\
1\end{array}$ & $\begin{array}{l}\text { Washed at Snack } \\
2\end{array}$ & $\begin{array}{l}\text { Washed at Snack } \\
2\end{array}$ & $\begin{array}{l}\text { Washed at Snack } \\
1 \& 2\end{array}$ & $\begin{array}{l}\text { Washed at Snack } \\
1 \& 2\end{array}$ \\
\hline \multirow{2}{*}{$\begin{array}{l}\text { Treatment: HOPE } \\
\text { SOAPO }\end{array}$} & $0.02^{a}$ & 0.04 & 0.11 & 0.06 & 0.10 & 0.10 \\
\hline & $(-0.13-0.18)$ & $(-0.12-0.20)$ & $(-0.06-0.29)$ & $(-0.11-0.23)$ & $(-0.08-0.27)$ & $(-0.07-0.27)$ \\
\hline Controls & No & Yes & No & Yes & No & Yes \\
\hline Observations & 230 & 228 & 188 & 187 & 188 & 187 \\
\hline R-squared & 0.00 & 0.12 & 0.01 & 0.17 & 0.01 & 0.13 \\
\hline
\end{tabular}

${ }^{\mathrm{a}}$ Beta coefficient presented followed by $95 \%$ confidence intervals in parentheses

*** $p<0.01,{ }^{* *} p<0.05, * p<0.1$

Additional controls included but not reported: female, age, household size, number of children in households (HH), asset ownership, piped water available in $\mathrm{HH}$, $\mathrm{HH}$ limits water use; soap observed in $\mathrm{HH}$; $\mathrm{HH}$ received hygiene training; caregiver depressed/anxious; child had difficulty opening tap; child cannot reach taps; child's hands too small for soap. The full model, with coefficients for all control variables, is presented in Additional file 1: Table S1

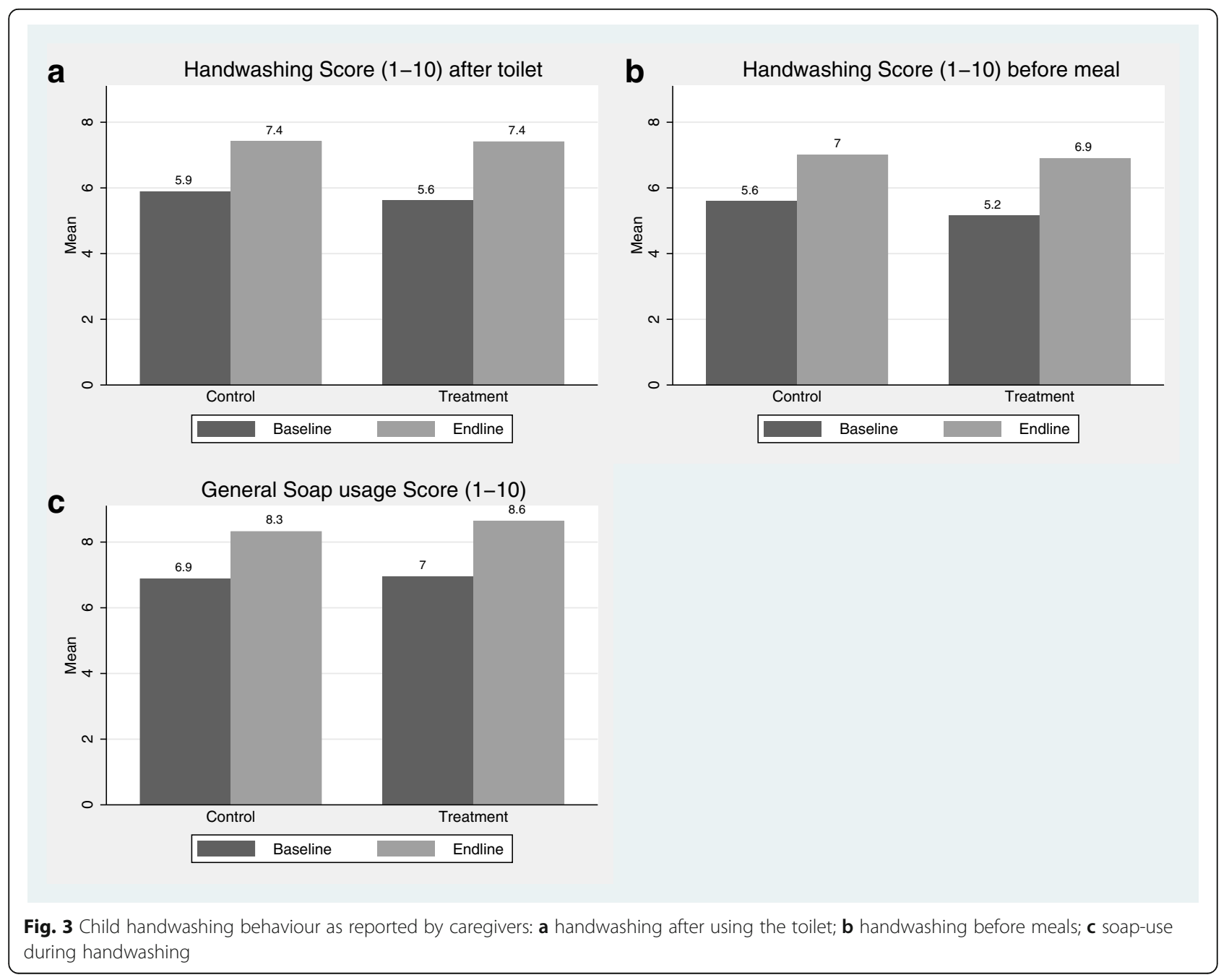


Table 4 Ordinary least squares regression models of treatment effects on handwashing outcomes among children (as reported by caregivers)

\begin{tabular}{|c|c|c|c|c|c|}
\hline \multirow[t]{2}{*}{ Panel A: Handwashing after toilet } & $\mathrm{A} 1$ & A2 & A3 & A4 & A5 \\
\hline & $\begin{array}{l}\text { Handwashing score } \\
{[1-10]}\end{array}$ & $\begin{array}{l}\text { Handwashing score } \\
{[1-10]}\end{array}$ & $\begin{array}{l}\text { Handwashing score } \\
{[1-10]}\end{array}$ & $\begin{array}{l}\text { Handwashing score } \\
{[1-10]}\end{array}$ & $\begin{array}{l}\geq 8 \text { on scale } \\
{[0 / 1]}\end{array}$ \\
\hline \multirow[t]{2}{*}{ Treatment: HOPE SOAP@ } & $-0.01^{\mathrm{a}}$ & 0.11 & 0.20 & 1.29 & 0.08 \\
\hline & $(-0.69-0.67)$ & $(-0.62-0.84)$ & $(-0.49-0.88)$ & $(-0.33-2.91)$ & $(-0.06-0.23)$ \\
\hline \multirow[t]{2}{*}{ baseline handwashing measure } & & & $0.22^{* * *}$ & $0.32^{* * *}$ & $0.29^{* * *}$ \\
\hline & & & $(0.10-0.34)$ & $(0.15-0.50)$ & $(0.15-0.43)$ \\
\hline \multirow{2}{*}{$\begin{array}{l}\text { Treatment*Baseline handwashing } \\
\text { measure }\end{array}$} & & & & $-0.19^{*}$ & \\
\hline & & & & $(-0.41-0.03)$ & \\
\hline Controls & No & Yes & Yes & Yes & Yes \\
\hline Observations & 249 & 247 & 242 & 242 & 242 \\
\hline R-squared & 0.00 & 0.08 & 0.16 & 0.17 & 0.16 \\
\hline \multirow[t]{2}{*}{ Panel B: Handwashing before meal } & B1 & B2 & B3 & B4 & B5 \\
\hline & Score $1-10$ & Score $1-10$ & Score $1-10$ & Score $1-10$ & $\geq 8$ on scale \\
\hline \multirow[t]{2}{*}{ Treatment: HOPE SOAP@ } & -0.10 & 0.27 & 0.28 & 1.14 & 0.05 \\
\hline & $(-0.86-0.65)$ & $(-0.49-1.03)$ & $(-0.46-1.02)$ & $(-0.46-2.73)$ & $(-0.08-0.19)$ \\
\hline \multirow[t]{2}{*}{ baseline handwashing measure } & & & $0.13^{* *}$ & $0.22^{* *}$ & 0.10 \\
\hline & & & $(0.01-0.25)$ & $(0.04-0.39)$ & $(-0.05-0.26)$ \\
\hline \multirow{2}{*}{$\begin{array}{l}\text { Treatment*Baseline handwashing } \\
\text { measure }\end{array}$} & & & & -0.16 & \\
\hline & & & & $(-0.40-0.09)$ & \\
\hline Controls & No & Yes & Yes & Yes & Yes \\
\hline Observations & 249 & 247 & 244 & 244 & 244 \\
\hline R-squared & 0.00 & 0.09 & 0.11 & 0.11 & 0.12 \\
\hline \multirow{2}{*}{$\begin{array}{l}\text { Panel C: General soap usage when } \\
\text { handwashing }\end{array}$} & $\mathrm{C} 1$ & $\mathrm{C} 2$ & C3 & C4 & C5 \\
\hline & Score $1-10$ & Score $1-10$ & Score $1-10$ & Score $1-10$ & $\geq 8$ on scale \\
\hline \multirow[t]{2}{*}{ Treatment: HOPE SOAP@ } & 0.31 & $0.42^{*}$ & 0.41 & 0.91 & $0.14^{* *}$ \\
\hline & $(-0.27-0.89)$ & $(-0.07-0.91)$ & $(-0.09-0.90)$ & $(-0.89-2.70)$ & $(0.03-0.24)$ \\
\hline \multirow[t]{2}{*}{ bBaseline handwashing measure } & & & $0.13^{* *}$ & $0.17^{*}$ & $0.15^{* *}$ \\
\hline & & & $(0.01-0.26)$ & $(-0.02-0.36)$ & $(0.02-0.28)$ \\
\hline \multirow{2}{*}{$\begin{array}{l}\text { Treatment*Baseline handwashing } \\
\text { measure }\end{array}$} & & & & -0.07 & \\
\hline & & & & $(-0.31-0.17)$ & \\
\hline Controls & No & Yes & Yes & Yes & Yes \\
\hline Observations & 249 & 247 & 236 & 236 & 236 \\
\hline R-squared & 0.01 & 0.07 & 0.10 & 0.10 & 0.13 \\
\hline
\end{tabular}

${ }^{a}$ Beta coefficient presented followed by $95 \%$ confidence intervals in parentheses

${ }^{\mathrm{b}}$ Baseline equivalent of dependent variable

*** $p<0.01,{ }^{* *} p<0.05,{ }^{*} p<0.1$

Additional controls included but not reported: Female, age, household size, number of children in $\mathrm{HH}$, asset ownership, piped water available in $\mathrm{HH}$, $\mathrm{HH}$ limits water use; soap observed in $\mathrm{HH}$; $\mathrm{HH}$ received hygiene training; caregiver depressed/anxious; child had difficulty opening tap; child cannot reach taps; child's

hands too small for soap. The full models, with coefficients for all control variables, are presented in Additional file 1: Tables S2, S3 and S4

weakening treatment effect among initially better handwashers (interaction term: $-0.19, p=0.093$ ). Model A5 shows a positive, but not statistically significant association between receipt of HOPE SOAP $\odot$ and the proportion at the top end of the handwashing score. Similar results are found in relation to the effect of HOPE SOAP $\odot$ on handwashing before meals as reported in Table 4, Panel B, although the results lack statistical power. 
HOPE SOAP $\odot$ children were significantly more likely to use soap when washing their hands

A more positive treatment effect was found on general soap use when children did wash their hands (Table 4, Panel C). The average soap use score was 0.42 higher $(p=0.094)$ among children in the HOPE SOAP( group than control children after including control variables (Model C2). At the top end of the scale (Model C5), the proportion scoring higher than eight was $14 \%$ points greater $(p=0.011)$ in the treatment group. Sensitivity analysis using a multivariable logistic regression model with the same specification as Model C5 also showed that children in the treatment group were significantly more likely to use soap when washing hands (adjusted odds ratio: 2.42, $p=$ 0.017).

HOPE SOAP $\odot$ children exhibited better health outcomes on average, although the differences were not statistically significant

A reduction in symptoms of illness experienced was observed for both treatment and control children. The average of the illness score (0-14) decreased from 2.5 to 1.7 among HOPE SOAP@ children and from 2.6 to 1.9 among children in the control group, with the average illness score marginally lower among treatment children at endline. A small treatment effect on health remained after controlling for baseline characteristics (Table 5). The average illness score was - 0.35 lower among HOPE SOAP॰ children (Model $3, p=0.256)$ and the proportion of HOPE SOAP॰ children who experienced any symptom of illness in the two weeks prior to the endline survey was $9 \%$ points lower (Model 7, $p=0.204$ ).
HOPE SOAP $\odot$ children who used the soap as intended exhibited significantly better health outcomes compared to the control group

The intention of HOPE SOAP@ was to encourage children to wash their hands more frequently in the process of retrieving the toy. However, children may have used other strategies to obtain the toy such as dissolving the soap in water or cutting the soap. In such cases children who received HOPE SOAP@ could end up worse off than control children because of decreased access to soap. We create an indictor ('toy-cheat') using responses from caregivers about whether the child ever retrieved the toy by (1) dissolving the soap in water, (2) cutting the bar of soap, or (3) destroying the soap in another manner. Notably, this is a blunt indicator as caregivers would have had to both observe and report this behaviour, and they could have reported this behaviour even if it only happened on one occasion. According to this measure, $42 \%$ of the treatment children were classified as toy-cheats. There was no evidence that toy-cheats had less access to soap than other children who received HOPE SOAPণ. Caregivers of toy-cheats and non toy-cheats reported a similar average for the number of days that a bar of soap lasted (8.4 vs 8.3).

Multiple regression models (Table 6) found that children who used the soap as intended (non toy-cheat) had a significantly lower illness score (Model 1 ) and were $15 \%$ points less likely $(p=0.049)$ to experience any illness in the two weeks prior to the endline survey compared to the control group (Model 2). In contrast, the difference in health between control group children and the toy-cheats was negligible. Sensitivity analysis using multivariable logistic regression analysis with the same specification as Model 2 also found that children in the treatment group who used HOPE SOAP $\odot$ as intended

Table 5 Ordinary least squares regression models of treatment effects on experience of illness

\begin{tabular}{|c|c|c|c|c|c|c|c|}
\hline & 1 & 2 & 3 & 4 & 5 & 6 & 7 \\
\hline & $\begin{array}{l}\text { Illness score [1- } \\
14]\end{array}$ & $\begin{array}{l}\text { Illness score [1- } \\
14]\end{array}$ & $\begin{array}{l}\text { IIIness score [1- } \\
14]\end{array}$ & $\begin{array}{l}\text { Illness score [1- } \\
14]\end{array}$ & $\begin{array}{l}\text { Any illness } \\
{[0 / 1]}\end{array}$ & $\begin{array}{l}\text { Any illness } \\
{[0 / 1]}\end{array}$ & $\begin{array}{l}\text { Any illness } \\
{[0 / 1]}\end{array}$ \\
\hline \multirow[t]{2}{*}{ Treatment: HOPE SOAP@ } & $-0.20^{\mathrm{a}}$ & -0.28 & -0.35 & -0.10 & -0.06 & -0.06 & -0.09 \\
\hline & $(-0.79-0.39)$ & $(-0.86-0.31)$ & $(-0.96-0.26)$ & $(-0.82-0.62)$ & $(-0.19-0.08)$ & $(-0.18-0.07)$ & $(-0.22-0.05)$ \\
\hline \multirow[t]{2}{*}{ Baseline illness measure } & & & $0.19^{* *}$ & $0.24^{* *}$ & & & $0.16^{* *}$ \\
\hline & & & $(0.04-0.34)$ & $(0.02-0.47)$ & & & $(0.01-0.31)$ \\
\hline \multirow{2}{*}{$\begin{array}{l}\text { Treatment*Baseline illness } \\
\text { measure }\end{array}$} & & & & -0.10 & & & \\
\hline & & & & $(-0.39-0.18)$ & & & \\
\hline Controls & No & Yes & Yes & Yes & No & Yes & Yes \\
\hline Observations & 249 & 247 & 236 & 236 & 236 & 236 & 236 \\
\hline R-squared & 0.01 & 0.07 & 0.10 & 0.10 & 0.09 & 0.07 & 0.13 \\
\hline
\end{tabular}

aeta coefficient presented followed by $95 \%$ confidence intervals in parentheses

${ }^{* * *} p<0.01,{ }^{* *} p<0.05,{ }^{*} p<0.1$

Additional controls included but not reported: Female, age, household size, number of children in $\mathrm{HH}$, asset ownership, piped water available in $\mathrm{HH}$, $\mathrm{HH}$ limits water use; soap observed in $\mathrm{HH}$; $\mathrm{HH}$ received hygiene training; caregiver depressed/anxious; child had difficulty opening tap; child cannot reach taps; child's hands too small for soap. The full model, with coefficients for all control variables, is presented in Additional file 1: Table S5 
Table 6 Ordinary least squares regression models of treatment effects on handwashing and health by correct use of HOPE SOAPC

\begin{tabular}{cll}
\hline & $(1)$ & $(2)$ \\
& Illness score [1-14] & Any illness [0/1] \\
\hline HOPE SOAPO (vs control) & & \\
Not a Toy-Cheat & $-0.61^{*}$ & $-0.15^{* *}$ \\
& $(-1.31-0.09)$ & $(-0.31--0.00)$ \\
Toy-Cheat & 0.07 & 0.02 \\
& $(-0.65-0.79)$ & $(-0.14-0.18)$ \\
Baseline illness measure & $0.19^{* *}$ & $0.16^{* *}$ \\
& $(0.04-0.34)$ & $(0.01-0.31)$ \\
Controls & Yes & Yes \\
Observations & 209 & 209 \\
R-squared & 0.23 & 0.23 \\
\hline
\end{tabular}

${ }^{\mathrm{a} B e t a}$ coefficient presented followed by $95 \%$ confidence intervals in parentheses

${ }^{* * *} p<0.01,{ }^{* *} p<0.05,{ }^{*} p<0.1$

Additional controls included but not reported: female, age, household size, number of children in $\mathrm{HH}$, asset ownership, piped water available in $\mathrm{HH}, \mathrm{HH}$ limits water use; soap observed in $\mathrm{HH} ; \mathrm{HH}$ received hygiene training; caregiver depressed/anxious; child had difficulty opening tap; child cannot reach taps; child's hands too small for soap. The full model, with coefficients for all control variables, is presented in Additional file 1: Table $\mathbf{S 6}$

were significantly less likely to have experienced any illness in the two weeks prior to the endline survey compared to the control group (adjusted odds ratio: $0.44, p=0.039$ ).

\section{Discussion}

There are a number of positive results from the HOPE SOAP@ pilot study which suggest real potential for this innovative soap product to increase and sustain handwashing among young children. Conditional on poor baseline handwashing behaviour, HOPE SOAP๔ children were more likely to wash their hands after using the toilet, albeit insignificantly so, and were also significantly more likely to use soap to wash their hands as opposed to just rinsing with water. Furthermore, a greater proportion of children in the HOPE SOAP $\odot$ group $(10 \%$ points) were observed to wash their hands unprompted both times they were offered a snack. This suggests there is merit in making handwashing a fun and goal-oriented activity, especially for children who do not regularly wash their hands. Moreover, HOPE SOAP๔ children, in general, had better health outcomes and those who used the soap as intended, and did not cheat to remove the toy from the soap, evidenced significantly better health outcomes.

Whilst there are a number of other positive results on reported handwashing behaviour, our results lack statistical power. This could be due to a number of factors, the most obvious being small sample size which is an inevitable feature of most pilot studies. Attrition between baseline and endline further reduced the sample, although the attrition rate for households from our baseline sample was only $13,5 \%$ and differences between the control and treatment group were not significant.

Spillover effects, both between and within households, may also serve to dampen estimated treatment effects. Whilst we stratify on the basis of household size and the adult to child ratio within the household when conducting the randomisation, it still remains the case that if the novelty of HOPE SOAP॰ induced other household members within the household to wash their hands more regularly than household members in the control group, the soap may have been depleted more quickly, thereby undermining potential health benefits for treated children. This could contribute to reduced treatment effects. In contrast, we do not think that between household spillovers constitute a serious problem in this study as fewer than $2 \%$ of treated children were reported to have shared their soap with children outside the household.

The magnitude of our treatment effect is also undermined by substantial increases in handwashing among children in control households during the study period. Control group children received child-sized, bright, translucent bars of soap. This soap was different than the usual household soap, and may itself have induced children in control households to wash their hands more frequently. Our data shows that the proportion of children whose caregivers reported "small hands" as a barrier to handwashing halved between baseline and endline (32 to 15\%). This effect was similar in both treatment and control groups suggesting that delivery of child-sized soap may itself be an important (and even sufficient) intervention to induce handwashing among children. Had control group children received normal household soap (typically larger in size and not as colourful), one might have anticipated larger treatment effects. Whilst we acknowledge that access to basic provision might sometimes act as a barrier to handwashing, in our sample, $80 \%$ of households had access to running water and flush toilets, making it difficult to argue that access to services was the key barrier to handwashing. Rather, it appears that lack of access to 'child-friendly' soap may constitute a more significant barrier in this particular instance. Further research is warranted as these findings point towards child-friendly soap, sized appropriately for ease of use by small hands, as a potential low-cost intervention to improve handwashing among children.

The overall health impacts associated with HOPE SOAP@ were not particularly strong. Children in both treatment and control groups appear to have enjoyed improved health between baseline and endline. This could be due to the increased handwashing induced by the availability of soap, which our data certainly suggests, but it 
could also reflect seasonal changes that may be associated with improved health, since the baseline was conducted in Spring and the endline was conducted during the summer months. However, despite this confound, the fact that HOPE SOAP@ children who used the soap as intended (ie, they did not cut or dissolve the soap to get the toy) enjoyed significantly better health outcomes compared to the control group is certainly encouraging. Furthermore, the health outcomes of children who were categorised as toy-cheats were similar to those in the control group, indicating that there were no unintended negative effects of the intervention on health.

Study results should be interpreted in the context of other potential limitations. It is possible that social desirability bias, recall bias and incorrect knowledge might have resulted in misreporting of handwashing and child health by caregivers during the baseline and endline surveys. However, there is no a priori reason to expect that this bias would be different across treatment and control groups. Although several measures were taken to minimise any bias resulting from community workers being non-blinded to study group assignment, it is possible that this introduced some bias in the estimation of the effect of HOPE SOAP@. This is a problem for any study that aims to collect observational measures of soap usage, our study is not unique, and we think such bias is likely to be minimal given our study design. In addition, the period between endline measurements and initiation of the intervention was relatively short. Further research is required to assess the impact of HOPE SOAPC on long-term habit formation.

\section{Conclusions}

Overall, results indicate that HOPE SOAP॰ does, indeed, give cause for hope. There is evidence that it may improve, and induce sustained handwashing behaviour among young children and, if used correctly, improve health outcomes. If HOPE SOAP@ can be produced and sold at the same price as regular soap it could well prove to be a more effective intervention than simple soap distribution. The results of our pilot study indicate that further research on this novel handwashing intervention is warranted.

\section{Endnotes}

${ }^{1} \mathrm{HOPE}$ SOAP $\odot$ was created through a partnership between advertising agency Young \& Rubicam (Y\&R) and Safety Lab, a non-profit behavioural innovation lab.

\section{Additional file}

Additional file 1: Hygiene education message. Table S1. Ordinary least squares regression models of treatment effects on handwashing during the Snack Tests. Table S2. Effect of treatment on handwashing after going to the toilet. Table S3. Effect of treatment on handwashing before meals. Table S4. Effect of treatment on general soap usage when washing hands. Table S5. Effect of treatment on child health. Table S6. Effect of treatment on handwashing and health by correct use of HOPE SOAP@. (DOCX 75 kb)

\section{Abbreviation \\ FCW: Foundation for Community Work}

\section{Acknowledgements}

We are grateful to Rachel Glennerster and seminar participants at the University of Cape Town for valuable comments on previous version of this manuscript and to Laura Costica and Emmanuel Bakirdjian for valuable suggestions on the research design. We gratefully acknowledge funding provided by the Abdul Latif Jameel Poverty Action Lab (J-PAL) Incubation Fund. We thank Young \& Rubicam, and Safety Lab for permission to test their product and for valuable research support. We are extremely grateful to the Foundation for Community Work and their team of Community Workers for invaluable assistance with developing the study design, implementation of the intervention and with data collection. We thank the social pensioners at Neighbourhood Old Age Homes (NOAH) for their effort and care in manufacturing high quaility soap for this study.

\section{Funding}

This work was supported by the The Abdul Latif Jameel Poverty Action Lab (J-PAL) Incubation Fund.

\section{Availability of data and materials}

The data that support the findings of this study are available from the authors on request.

\section{Authors' contributions \\ $J B$ and $B M B$ conceptualised the study. JB, BMB, and AM designed the study; and were responsible for study operations. AM was responsible for quality assurance. All authors contributed to data analysis, the interpretation of the data, and manuscript preparation. All authors approved the final version of the manuscript.}

\section{Ethics approval and consent to participate}

This work was approved by the Ethics in Research Committee in the Faculty of Commerce at the University of Cape Town (Application number 1952). All procedures performed in studies involving human participants were in accordance with the ethical standards of the institutional and/or national research committee and with the 1964 Helsinki declaration and its later amendments or comparable ethical standards. Written consent for the surveys was obtained from all respondents. No minors were interviewed during the study.

Competing interests

The authors declare that they have no competing interests.

\section{Publisher's Note}

Springer Nature remains neutral with regard to jurisdictional claims in published maps and institutional affiliations.

\section{Author details}

${ }^{1}$ School of Economics, University of Cape Town, Private Bag, Rondebosch 7701, South Africa. ${ }^{2}$ Southern Africa Labour and Development Research Unit, University of Cape Town, Private Bag X3, Rondebosch 7701, South Africa. ${ }^{3}$ Abdul Latif Jameel Poverty Action Lab, University of Cape Town, Private Bag, Rondebosch 7701, South Africa.

Received: 2 October 2017 Accepted: 17 May 2018

Published online: 07 June 2018

\section{References}

1. Aiello AE, Coulborn RM, Perez V, Larson EL. Effect of hand hygiene on infectious disease risk in the community setting: a meta-analysis. Am J Public Health. 2008;98:1372-81. 
2. Van Lerberghe W, Manuel A, Matthews Z, Cathy W. The World Health Report 2005: Make every mother and child count. Geneva: World Health Organisation; 2005. http://www.who.int/whr/2005/whr2005_en.pdf. Accessed 23 September 2017

3. Almond D, Currie J. Human capital development before age five. NBER Working Paper Series. 2011;15827

4. Currie J, Stabile M, Manivong P, Roos LL. Child Health and Young adult outcomes. J Hum Resour. 2010;45:517-48.

5. Case A, Paxson C. Early life health and cognitive function in old age. Am Econ Rev. 2009;99:104-9.

6. Chay K, Guryan J, Mazumder B. Birth cohort and the black-white achievement gap: the roles of access and health soon after birth. NBER Working Paper. 2009;15078

7. Lorntz B, Soares AM, Moore SR, Pinkerton R, Gansneder B, Bovbjerg VE, et al. Early childhood diarrhea predicts impaired school performance. Pediatr Infect Dis J. 2006;25:513-20.

8. Galiani S, Gertler P, Orsola-Vidal A. Promoting handwashing behavior in Peru: the effect of large-scale mass-media and community level interventions. World Bank Policy Res Working Paper. 2012;6257

9. The World Bank. The hand-washing handbook: a guide for developing a hygiene promotion program to increase hand-washing with soap. In: The World Bank; 2005.

10. Chase C, Do Q-T. Scaling up handwashing behavior: findings from the impact evaluation baseline survey in Vietnam. Water and Sanitation Program; 2010. https://www.wsp.org/sites/wsp.org/files/publications/WSP_ VietnamBaselineReport_HWWS.pdf. Accessed 23 Sept 2017

11. Marteau TM, Hollands GJ, Fletcher PC. Changing human behavior to prevent disease: the importance of targeting automatic processes. Science. 2012;337:1492-5.

12. Neal D, Vujcic J, Hernandez O, Wood W. The science of habit: creating disruptive and sticky behavior change in handwashing behavior. Washington D.C.: USAID/WASHplus Project; 2015. http://www.washplus.org/ sites/default/files/resource_files/habits-neal2015.pdf. Accessed 23 Sept 2017

13. Vindigni SM, Riley PL, Jhung M. Systematic review: handwashing behaviour in low-to middle-income countries: outcome measures and behaviour maintenance. Tropical Med Int Health. 2011;16:466-77.

14. Wood W, Tam L, Witt MG. Changing circumstances, disrupting habits. J Pers Soc Psychol. 2005;88:918-33.

15. Luby SP, Agboatwalla M, Feikin DR, Painter J, Billhimer W, Altaf A, et al. Effect of handwashing on child health: a randomised controlled trial. Lancet. 2005;366:225-33.

16. Bowen $\mathrm{A}$, Ma H, Ou J, Billhimer W, Long T, Mintz E, et al. A clusterrandomized controlled trial evaluating the effect of a handwashingpromotion program in Chinese primary schools. Am J Trop Med Hyg. 2007; 76:1166-73

17. Greenland K, Iradati E, Ati A, Maskoen YY, Aunger R. The context and practice of handwashing among new mothers in Serang, Indonesia: a formative research study. BMC Public Health. 2013;13:830

18. Ram P. Practical Guidance for Measuring Handwashing Behavior: 2013 Update. In: The Water and Sanitation Program, World Bank; 2013. https:// www.wsp.org/sites/wsp.org/files/publications/WSP-Practical-GuidanceMeasuring-Handwashing-Behavior-2013-Update.pdf. Accessed 23 Sept 2017.

19. Nkuna B. Diarrhea kills increasing numbers of under 5 's. In: West Cape News; 2009. http://westcapenews.com/?p=470. Accessed 23 January 2018.

20. Duflo E, Glennerser R, Kremer M. Using randomization in development economics research: a toolkit. Centre for Economic Policy Research Discussion Paper Series. 2007:6059

\section{Ready to submit your research? Choose BMC and benefit from:}

- fast, convenient online submission

- thorough peer review by experienced researchers in your field

- rapid publication on acceptance

- support for research data, including large and complex data types

- gold Open Access which fosters wider collaboration and increased citations

- maximum visibility for your research: over $100 \mathrm{M}$ website views per year

At BMC, research is always in progress.

Learn more biomedcentral.com/submissions 